\title{
PROFILE OF VISITORS TO CULTURAL HERITAGE ATTRACTIONS IN BULGARIA
}

DOI: http://dx.doi.org/10.18509/GBP.2020.44

UDC: 338.48-6:930.85-052]:303.62(497.2)

\author{
Vasil Marinov \\ Mariana Assenova \\ Vera Nikolova \\ Atanas Kazakov \\ Radenka Mitova \\ Elena Petkova
}

Geography of Tourism Department, Faculty of Geology and Geography, Sofia University “St. Kliment Ohridski”, Bulgaria

\begin{abstract}
The overall objective of the study is to collect empirical information on the supply and demand of cultural heritage attractions in Bulgaria, and the specific objective is to outline a detailed profile of visitors to tourist attractions based on cultural heritage. The methodological toolkit includes preliminary desk research of the selected attractions, semi-structured interviews with the "operators" of cultural heritage attractions, questionnaire survey of visitors to cultural heritage attractions, as well as observations and expert assessments. The visitor typology is based on the methodology proposed by McKercher (2002). It aims to create a more precise classification (segmentation) of "cultural tourists" and is based on a combination of two dimensions - the importance of cultural motives (cultural tourism) in the decision to visit the destination and the depth of experience associated with the culture and heritage of the destination. Altogether 668 visitors were interviewed at 30 sites, identified as cultural heritage tourist attractions.

The questionnaire design and the data obtained allow the outlining of a detailed profile of visitors in terms of their socio-demographic characteristics, and the characteristics of the trip, respectively of the tourists' behavior. A visitor typology in terms of cultural tourism is elaborated, including the profile of each of the distinguished types. Their relationship with visitor and travel characteristics is revealed and analysed. The results indicate that the cultural tourist type in most cases is a variable that explain the differentiation in visitors' behaviour better than the typically used socio-demographic characteristics.
\end{abstract}

Keywords: cultural heritage, tourist attractions, visitors, tourist behavior, typology

\section{INTRODUCTION}

The thorough knowledge of the motives and behavior of cultural tourists, helps destination managers not only to apply appropriate interpretation and educational programs but also to imply suitable visitor management measures. However, when we examine the situation, it appears that preservation and the marketing programs concerning heritage sites were often not based on in-depth and thorough scientific studies of the practices and behavior of their visitors. This is exactly the situation in Bulgaria. Evident is not only the lack of data concerning characteristics, motivation and behavior of cultural tourists but also the lack of a definition of the issue of cultural tourism practices. The 
information gap has been recently highlighted in the product analysis of cultural tourism [1] prepared for the elaboration of the National plan for development of cultural tourism 2020-2025 [2], emphasizing more specifically the lack of up-to-date data on the profile, needs, preferences and satisfaction of cultural tourists.

Filling the above-mentioned information gap the paper presents the profile of visitors of cultural heritage attractions in Bulgaria. Based on a thorough in-depth study it outlines the socio-geographic characteristics, as well as the features of travel and information behavior of domestic and international tourists at particular cultural heritage sites. Not all cultural tourists have the same requirements and express the same behavior during their visits at heritage sites. Therefore, the study provides a typology of cultural heritage tourists in Bulgaria.

\section{LITERATURE REVIEW}

Literature sources reveal the characteristics of cultural tourists that should be studied. There are numerous specific studies of the profiles of cultural tourists in a wide number of regions of the world. Moreover, literature provides some significant classifications of cultural tourists, too.

Some authors present the aspects of tourists and in particular cultural tourists that should be examined $[3,4]$. They include socio-demographic characteristics and features of the behavior of the travelers before, during and after the visits of culture heritage sites. It is important to know where the customers come from, what is the range from which domestic visitors come and what is the dominant country of origin for foreign markets [4]. Other demographic characteristics are the age and gender structure of the visitors [4]. In terms of pre-trip motivation, the researchers should answer the questions why did the tourists decide to visit the sites and what experiences or recreational learning opportunities they were looking for [3]. The study of the tourists after the trip should explain what the level of tourist satisfaction is [4]. Researchers might answer questions such as did the site meet, exceed or fall short of visitors' 'expectations' of what they would see, do and experience, what were their best or most powerful 'memories' of their visits and what reasons we give them to return again to this attraction [3]. The range of the characteristics of behavior of tourists at cultural and heritage sites that can be studied is wide - how they arrived at the attractions, what transport mean they used, whether they came alone or in small groups of family and friends or within tour-organized groups [4]. Other questions that researchers should answer are how long the average visit lasts, is there a perception that the admission fee is a good value for the experience, what visitors spent money on and how much, what visit components were of most importance to tourists, etc. [3].

Profiles of heritage tourists based on socio-demographic and trip characteristics, as well as on their motivations are common. These studies focus on tourists who either come from particular countries or visit heritage sites at specific regions of the world $[5,6,7,8$, $9,10]$. The results of the studies reveal common characteristics in terms of sociodemographic features, specifics of trips and motivations of culture and heritage tourists. Cultural tourists are usually older [8]. Most often they are within 45-64 age groups [5], though sometimes they are younger - around 39 years old [7]. However, in some regions, cultural tourists are not old, most often being well-educated students [10]. Heritage tourists are often well educated [6], more likely to have a post-high school education [8] and to be qualified professionals [7, 10]. Cultural tourists have above average [5] or high income [8]. Regarding the characteristics of the trip, culture and heritage tourists are 
generous in spending [6] and usually spend more money per trip [8]. Heritage tourists travel mostly during the summer months $[5,8]$. They tend to travel as a couple $[5,7]$ or with family [7] and are more likely to participate in a group tour [8]. Heritage tourists are inclined to stay longer than the average $[6,8]$ and came back more often than other types of tourists [8]. These tourists require high quality of services [6]. Culture and heritage tourists participate at least in one cultural, arts, history or heritage activity [8], such as sightseeing, visiting heritage sites and museums [9], historic and religious monuments or vermicular buildings, ruins, etc. [5]. As regards the motivation culture and heritage tourists often seek genuine or authentic experiences [6, 7]. They want things that feel real and like living culture, history and the outdoors [7]. Learning experiences usually draw these tourists [5]. They want to learn and expand their personal boundaries but are also interested in relaxing in a pleasant place with many amusing activities [9]. Another leading factor of the motivation of culture and heritage tourists is discovery [5]. They want to feel like explorers and enjoy new experiences [7]. For them experiencing destination's most interesting sights and culture is a key driver for where they go on holiday [7]. Other important motivators are contacts with people [5]. Heritage tourists seek travel experiences that broaden and deepen their understandings of other places and people, they want to experience destinations with a distinctive sense of place [6].

Other authors study in-depth cultural tourists' experiences. A study performed in Istanbul [11] determines five groups of factors affecting cultural tourists' overall travel experiences. The first group ('social interaction') includes characteristics of locals, described such as helpful, polite, friendly, etc. The second one ('local authentic clues') is related to the novel and authentic perceptions that symbolize the locality and are different from home and other destinations. The third group ('service') incudes tourism attractions and service facilities at the destination. The forth one ('culture/ heritage') encompasses heritage, art, history, entertainment, fashion, clothing, cultural events, architecture and food. The last one ('challenge') considers aspects, such as shopping, traffic, noise, etc. Therefore, not only heritage and culture affect the experience of cultural tourists but also factors, such as availability of things that are different from other destinations, interactions with local people, services offered at the place and the environment.

Richards (2011) outlines some recent qualitative trends in cultural tourists' visits growing interest in popular culture of the destination, growing role for the arts in cultural tourism, increased linkage between tourism and creativity and growing omnivorousness of cultural consumption [12]. In the field of creative tourism the emphasis shifts from tangible to intangible culture, and the basic experience consists of an exchange of knowledge and skills between host and guest. People develop their own skills and experience local culture at the same time [13]. Modern cultural tourists take part in all forms of culture. People are no longer interested in one narrow form of culture. They are selecting elements from a wide range of cultural forms to create their own identity [14]. The main point of creative tourism is providing authentic travel experiences through participatory learning activities. Some cities' authorities now view tourists as 'temporary citizens' who stay for a shorter or longer time in the city and interact with all aspects of local life [15]. Due to these trends, "in the future, much more effort should be applied to studying the practices of cultural tourism, which form a system that includes the materials providing the basis of the cultural tourism practice (e.g. tangible and intangible heritage, contemporary culture and creativity), the meanings that people attach to the practice (e.g. learning, identity, narrative and storytelling) and the competences that are developed 
through the practice (e.g. ways of 'doing' cultural tourism, reading and interpreting cultural heritage)" [16]. Therefore, modern cultural tourists not only want to enhance their knowledge and develop their skills but also want to experience local way of life and relate it to their identities. That is the reason why the 'new' cultural tourists are searching for novel and various experiences that link tangible and intangible heritage with contemporary culture.

However, not all tourists visiting heritage sites possess all the characteristics stated above. Xie and Wall (2002) claim that not all visitors to cultural attractions experience culture as a high priority [17]. Authenticity is not high priority among many visitors. The decision to visit may not be their own and they may have few expectations. They might lack the time and the depth of experience to understand the more complex and intricate aspects of local cultures. However, many visitors may be interested in and enjoy cultural activities and, through the selected presentation of the cultural attributes, they may acquire a stereotypical view of local cultures [17].

Some authors claim that various people visiting cultural sites want to have different experiences. According to Cenderello (2015) among the cultural tourists there are people who are looking for a deep cultural and educational experience, they have a desire to learn the physical attributes of the site and its background. Some people are looking for a personalized heritage experience as a means to achieve an emotional involvement with the site. Other visitors of heritage sites like to enjoy themselves and look for something interesting to do while on holiday [18].

Many studies point out that there are different kinds of cultural and heritage tourists. The different types of cultural tourists might have various requirements, characteristics and behavior, be motivated by different aspects of heritage and have different experiences at sites. That is why the typology of cultural tourists is rising in importance.

A study based on a survey conducted in Arizona, USA [19], segmented heritage tourists into two groups and five subgroups based on their most influential reasons for taking the trip. The first primary group of true cultural tourist is subdivided into two subgroups, site and event visitors, who stated the most influential reason for taking the trip was participation in cultural, arts or heritage activities, or attending a special event or festival. The second primary group of spurious cultural tourists included the remaining visitors. This group consisted of three subgroups divided by the most influential activity - nature, sports and business. The study found that cultural sites and cultural events tourists are very different in terms of demographics, importance of different types of cultural attractions and motivations. This classification takes into account only whether culture and heritage are the main reason to travel. However, cultural tourists also differ in terms of the activities they participate in, by their interests and desire to learn, the time spent and the behavior at cultural sites.

Nyaupane et al. (2006) developed a more thorough classification of cultural tourists [20]. Based upon motives for cultural history learning and experiencing cultural heritage, three distinct segments of tourists to cultural heritage sites in Arizona, USA were found: (1) 'culture-focused'; (2) 'culture-attentive' and (3) 'culture-appreciate' tourists. One-third of the tourists were culture-focused, one-half were culture-attentive and less than onefifth were culture-appreciate. These groups differed significantly in terms of recreation behavior, emotional and learning experiences, interpretation, and interests in educational facilities, programs and services. The culture-focused segments spent longer time at the sites, stayed more nights away from home, engaged more frequently in on-site activities and placed more importance on cultural history learning motives, followed by cultural- 
attentive tourists. Visiting archeological sites was the most common primary activity for the culture-focused group, whereas walking and taking photos were the most popular primary activities for the culture-appreciate group. In addition, the culture-focused groups were more satisfied with their trips, appreciated the preservation of archeological resources and reported more learning experiences, followed by the culture-attentive tourists. The typology segments cultural tourists by a wide range of factors like their learning experiences, time spent at the sites, participation in on-site activities, etc. However, the model is one-dimensional and therefore does not consider for example how many people who reported more learning experiences performed the primary activities visiting archeological sites and how many - walking and taking photos, etc. This issue can be resolved by using a two-dimensional model.

McKercher (2002) developed a two-dimensional model and tested it empirically in Hong Kong [21]. This typology classifies cultural tourists in five groups according to two dimensions simultaneously, namely the importance of cultural motives in the decision to visit a destination (centrality) and the depth of (learning) experience. Learning about other's culture or heritage is a major reason for visiting a destination for the first type of the purposeful cultural tourists (high centrality/ deep experience). They had a deep cultural experience and acquired a deep understanding of the history and culture of the region. Learning about the other's culture and heritage is a major reason for visiting a destination for the second type - the sightseeing cultural tourists (high centrality/ shallow experience) too. However, this type of tourists have a shallower, entertainment-oriented experience. Cultural tourism reasons play a limited role in the decision to visit a destination for the third type of the casual cultural tourist (modest centrality/ shallow experience). This type of cultural tourist engages the destination in a shallow manner. Cultural tourism plays little or no meaningful role in the destination decision-making process for the fourth type of the incidental cultural tourist (low centrality/ shallow experience), but while at the destination, the person will participate in cultural tourism activities, having a shallow experience. Cultural tourism plays little or no role in the decision to visit a destination for the fifth type of the serendipitous cultural tourist (low centrality/ deep experience), but while there this type of cultural tourist visits cultural attractions and ends up having a deep experience. The five identified segments of cultural tourists exhibited substantially different behavior.

The level of the acquired knowledge about history and culture of the destination is the only determinant of tourists' depth of experience. Similarly, only whether cultural tourism is the main reason to travel determines the importance of cultural motives in the decision to visit a destination. That is why, Mc Kercher and du Cros (2003) developed the typology further in order to include other criteria for evaluation of the cultural tourism motivation and the depth of experience [22]. They tested the identified segments of cultural tourists against of a wider range of trip, demographic, experiential, motivational, attitudinal and learning variables. The study results revealed that the spectrum of cultural tourists ranges from recreational or pleasure tourists who happen to participate in some cultural tourism activity to augment their trip experience to those people who travel exclusively or primary to pursue cultural tourism activities. "The purposeful cultural tourist is not just motivated to travel for deep cultural experiences. This person, in general, sees travel as a chance for self-development and seeks experiences that will facilitate the achievement of that goal. Likewise, incidental or casual cultural tourists are not superficial consumers of culture. These people see travel as recreation, refreshment and replenishment and seek experiences that help them achieve these goals" [22]. The 
modified model has certain scientific contribution and allows some valuable conclusions to be drawn. However, there are some issues with it - the authors did not explain why they choose the specific determinants or did not choose others. For example, one of the activities according to which tourists are classified is shopping. It is not clear why shopping, as an activity should be used in order to classify the participants in cultural tourism.

The review of primary and secondary data provided in the product analysis of cultural tourism in Bulgaria [1] helps to identify the recent demand for cultural tourism and the profile of visitors to cultural heritage attractions. In general, cultural tourism occupies a significant place in Bulgaria's product portfolio as a tourist destination. But as of $2014-$ 2015 , the country is still not well recognized as a destination for cultural tourism - only $15 \%$ of Bulgarians and 1,5\% of foreigners associate it spontaneously with culture, cultural sites and places, although $43 \%$ of Bulgarians and $29 \%$ of foreigners are familiar with Bulgaria's opportunities for cultural tourism.

According to 2009-2010 surveys, cultural tourism is among the most practiced types of tourism in the country - by $23 \%$ of Bulgarians and by $52 \%$ of foreigners. However, later surveys (2014-2015) show a substantial decline in that share - respectively, only $17 \%$ of Bulgarians and $9 \%$ of foreigners indicate involvement in cultural tourism experiences. At the same time, significant potential is outlined - $64 \%$ of Bulgarians and $42 \%$ of foreigners are inclined to practice cultural tourism in Bulgaria. According to the same report [1], in $201751 \%$ of Bulgarians and $61 \%$ of EU residents have visited a historical monument or site, $41 \%$ of Bulgarians and $52 \%$ of Europeans have attended a traditional event, and $38 \%$ of Bulgarians and $50 \%$ of Europeans have visited a museum or gallery. Foreign tourist arrivals related to cultural tourism show practically insignificant seasonal differences. In 2009 cultural tourism is a leading type of practiced tourism in autumn and spring, second in summer (after sea tourism) and third in winter (after ski and spa tourism).

The profile of visitors for cultural tourism, according to available research presented in the report [1], is as follows:

- Foreigners (according to 2009-2010 data) - more than half of them (54\%) are men, aged 36-55 years (49\%) or 15-35 years (36\%), mostly occupied (73\%), of which $20 \%$ on managerial positions, mainly with higher education $(68 \%)$. More than half of them $(55 \%)$ have visited Bulgaria before. They are attracted mainly by cultural and historical sites $(21 \%)$, low prices $(17 \%)$ and nature $(13 \%)$. The average stay is one week (6,4 nights) and the average daily expenses - 80 EUR. $73 \%$ of those practicing cultural tourism have visited two or more different places (average 3 ).

- Bulgarians (according to 2014 data) - more than half of them (56\%) are women of all age groups, but with an increased share of the group 15-29 years (30\%), mostly occupied (69\%), of which $9 \%$ on managerial positions, mainly with university (43\%) or secondary education (48\%). They undertake between 2 and 3 trips per year and have spent just under 250 EUR on their last trip.

\section{METHODOLOGY}

The methodological toolkit includes preliminary desk research of the selected attractions, semi-structured interviews with the "operators" of cultural heritage attractions, questionnaire survey of visitors to cultural heritage attractions, as well as observations and expert assessments.

The field research, incl. the visitor survey has been carried out between $25^{\text {th }}$ of June and $1^{\text {st }}$ of July 2019 by three experts (lecturers) and 30 tourism students from Sofia University. 
Altogether 668 respondents were interviewed at 30 culture heritage atractions, located in four areas - Koprivshtitsa-Hisarya-Kazanluk (region Rose valley), Veliko TarnovoGabrovo-Tyavna (Balkan region), Rousse and nearby sites (Danube region) and LovechPleven (parts of Danube and Balkan region). The criteria for selecting the areas and attactions aim to provide a diverse set of sites according to the elaborated typology [23] - by their nature cultural or scientific sphere to which they are related, historical period, type of environment, spatial structure, scope, etc.

Face-to-face interviews were applied using a standardized questionnaire. Visitors have been approached mainly when they go out of the site (exit-survey) to ensure availability of real impressons and experiences with the specific attraction. In sampling, a balanced representation was sought by criteria such as nationality and country of origin (usual residence), as well as gender and age. The questionnaire includes 26 questions that generate about 120 primary variables for statistical processing. The questions are mostly closed (23), but half of them (13) allow additional comments ("other") or free answers. In the data analysis, for cross-tabulation statistical significance tests (Pearson $\chi 2$, t-test) and connectivity coefficients $-\varphi_{c}$ (Cramer's V) were applied.

Two types of variables were used in drawing the visitors profile: socio-demographic characteristics (nationality and residence, gender and age, education, occupation, income), and the characteristics of the trip, respectively of the tourists' behavior (main purpose of visit, type and organization of the trip, form of conducting, composition of the social group, transport to reach the visited attraction, stay in the area of attractions, average daily expenditures as well as sources of information used about a specific attraction.

The methodology of McKercher [21] for typology of cultural tourists has been applied with minor modifications.

\section{RESULTS}

\section{Typology of visitors (cultural tourists)}

The same wording of the questions was used to specify the culture motivation and the depth of learning experience. The differences to the orginal methodology of McKercher are threefold. The main difference is in the sample - McKercher surveys Hong Kong visitors for different purposes, so he pre-filters them (based on practiced activities, places visited, etc.) to "extract" those with cultural motivation. Our study examines visitors to heritage attractions, assuming that they have some cultural motivation (regardless of the stated main purpose of the trip). Another difference is that in the depth-of-experience question, a possible answer "not relevant to me" has been added (this explains the nonclassified cases). Finally, due to the small number of cases in the types "casual" and "incidental", cultural tourist were combined under the heading "incidental" more so the difference between them is minor.

The results (Table 1) show that the own study is featured by higher share of purposrful and sightseeing cultural tourists and lower share of casual and incidental tourists. The differences may be due to different reasons, including the specific features of the countries (Bulgaria and Hong Kong), but may also be related to the methodology. Most importantly, the approach to identifying respondents was different - in our case they were identified when visiting heritage attractions, while McKercher derives them on the basis of practicing cultural activities (probably including contemporary culture). 
Table 1. Typology of visitors of heritage attractions by importance of cultural motivation and the depth of experience - methodology and results

\begin{tabular}{|lcccc|}
\hline & \multicolumn{2}{c|}{ Dimensions, scores (1-5) } & \multicolumn{2}{c|}{ Results, \% } \\
\hline Type & $\begin{array}{c}\text { Importannce of } \\
\text { cultural motivation }\end{array}$ & $\begin{array}{c}\text { Depth of } \\
\text { experience }\end{array}$ & $\begin{array}{c}\text { McKercher } \\
(2002)\end{array}$ & Own study \\
\hline Purposeful cultural tourist & 4,5 & 3,4 & $11,8 \%$ & $23,5 \%$ \\
\hline Sightseeing cultural tourist & 4,5 & 1,2 & $30,7 \%$ & $48,4 \%$ \\
\hline Casual culturall tourist & 3 & 1,2 & $27,9 \%$ & $14,1 \%$ \\
\hline Incidental cultural tourist & 1,2 & 1,2 & $23,5 \%$ & \\
\hline Serendipitous cultural tourist & $1,2,3$ & 3,4 & $6,2 \%$ & $3,4 \%$ \\
\hline Non-classified & & & n.a. & $9,0 \%$ \\
\hline
\end{tabular}

The types of cultural tourists are used to analyze and present the profive of visitors as the more detailed analysis involving cross tabulation by most of characteristics of visitors and of their trips revealed the highest explanation power of these types.

\section{Socio-demographic characteristics of the visitors}

Table 2 presents the socio-demographic profile of the visitors of heritage attractions broken down by type of cultural tourist.

Nearly $63 \%$ of the respondents are Bulgarians and foreigners are just over $37 \%$. For $61 \%$ of the respondents the usual place of residence is in Bulgaria, and for $39 \%$ - in another country. The cross-tabulation of respondents by nationality and country of origin identifies segments that seem not to have been addressed in the marketing of heritage attractions - Bulgarians living abroad (2,7\% of the total sample and $4,3 \%$ of the surveyed Bulgarians) and foreigners living in Bulgaria (who are $0,9 \%$ of the total sample and 2,4\% of the interviewed foreigners). Non-residents are coming from 35 countries. Most numerous are the visitors from other European countries (54\%), mainly from Germany (9\%), UK (7\%), Switzerland, Spain, Italy (6\% each) followed by the distant markets (38\%), mainly from USA (23\%), Australia (5\%), Japan (4\%), Canada and China (2\% each). As for the Bulgarian visitors only between $9 \%$ and $25 \%$ (for the different study areas) are local demand, from the same administrative region (NUTS 3).

The differences in the country of origin by types of cultural tourist are significant, but not large. Residents in Bulgaria have an above the average share of incidental cultural tourists $(18,4 \%)$, and non-residents - an above the average share of purposeful $(27,3 \%)$ and sightseeing cultural tourists $(53,5 \%)$. Visitors from neighboring countries have a much higher share of sightseeing $(64,3 \%)$, from other European countries - of purposeful cultural tourists $(29,8 \%)$, and from other (distant) countries - of purposeful $(26,7 \%)$ and sightseeing $(59,4 \%)$ cultural tourists. In addition, the share of incidental cultural tourists is much lower for visitors from distant countries $(7.9 \%)$.

Women dominate in the sample (62.5\%). This is more pronounced for Bulgarins $(66.2 \%)$ than for the foreigners (56.4\%), but there is no significant difference according to the type of tourists.

The sample contains a large enough number of respondents of all age groups. Highest is the share of the youngest (15-24 years - 22\%) and of the oldest (65 years and over - 20\%). Among the Bulgarians, the share of the youngest is higher (15-24 years - 26.5\%) and the share of the oldest is reduced (65 years and over - 14.5\%). The share of the oldest is higher among foreigners $(28.6 \%)$. The differences by type of tourist are significant but not substantial. The younger (between 15 and 44 years) are more often than the average incidental cultural tourists (17-27\%), and in particular the groups 25-34 and 35-44 have a lower share of purposeful cultural tourists (17-19\%). In contrast, the older (over 45 
years) are more often purposeful cultural tourists (27-29\%). The group 45-54 years is featured by a higher share of serendipitous tourists $(36 \%)$.

$2 / 3$ of the respondents are university graduates $-65,7 \%$ (bachelor's degree $-34,7 \%$, master's degree $-26,5 \%$ and $\mathrm{PhD}-4,5 \%), 1 / 4$ have secondary school education $(24.6 \%)$ and less than $10 \%$ - primary or lower education. Among the visitors from Bulgaria the share of university graduates is 2,3 times higher than their share in the population of the country, and the share of persons with secondary and primary education is almost 2 times lower. The difference is even greater among foreign visitors - the proportion of university graduates is 3 times higher than that of the EU population, while the share of persons with secondary education is 3 times smaller and of those with primary and lower education 8 times smaller.

Table 2. Socio-demographic profile of visitors of heritage attractions

\begin{tabular}{|c|c|c|c|c|c|c|c|c|}
\hline & & & Type o & cultura & tourist & & & \\
\hline & & $\stackrel{\pi}{0}$ & $\begin{array}{l}\text { ב. } \\
0 \\
0 \\
0 \\
0 \\
\vdots \\
0\end{array}$ & 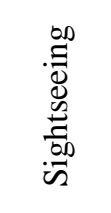 & $\begin{array}{l}\bar{\Xi} \\
\frac{\pi}{0} \\
\frac{\pi}{0} \\
\Xi \\
\Xi\end{array}$ & 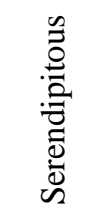 & 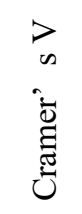 & 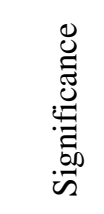 \\
\hline Country of origin & Resident (Bulgaria) & $61,0 \%$ & $54,8 \%$ & $57,0 \%$ & $72,1 \%$ & $73,9 \%$ & & \\
\hline - summarized & Non-resident (other) & $39,0 \%$ & $45,2 \%$ & $43,0 \%$ & $27,9 \%$ & $26,1 \%$ & 0,16 & $0,002^{2}$ \\
\hline & Bulgaria & $61,0 \%$ & $54,8 \%$ & $57,0 \%$ & $72,1 \%$ & $73,9 \%$ & & \\
\hline Country of origin & Neighboring countries & $4,2 \%$ & $3,2 \%$ & $5,6 \%$ & $3,8 \%$ & $0,0 \%$ & & \\
\hline - groups & Other European countries & $19,6 \%$ & $24,8 \%$ & $18,9 \%$ & $16,3 \%$ & $17,4 \%$ & 0,11 & $0,023^{\circ}$ \\
\hline & Other & $15,1 \%$ & $17,2 \%$ & $18,6 \%$ & $7,7 \%$ & $8,7 \%$ & & \\
\hline & Male & $37,5 \%$ & $39,6 \%$ & $36,0 \%$ & $38,2 \%$ & $34,8 \%$ & & \\
\hline Sex & Female & $62,5 \%$ & $60,4 \%$ & $64,0 \%$ & $61,8 \%$ & $65,2 \%$ & 0,04 & 0,931 \\
\hline & $15-24$ & $22,1 \%$ & $20,5 \%$ & $21,9 \%$ & $26,9 \%$ & $13,6 \%$ & & \\
\hline & $25-34$ & $13,6 \%$ & $9,6 \%$ & $12,5 \%$ & $17,3 \%$ & $22,7 \%$ & & \\
\hline & $35-44$ & $16,1 \%$ & $12,8 \%$ & $16,9 \%$ & $19,2 \%$ & $9,1 \%$ & 012 & \\
\hline Age & $\overline{45-54}$ & $15,3 \%$ & $17,9 \%$ & $14,4 \%$ & $13,5 \%$ & $36,4 \%$ & 0,12 & $0,021^{2}$ \\
\hline & $55-64$ & $12,9 \%$ & $14,7 \%$ & $15,0 \%$ & $8,7 \%$ & $13,6 \%$ & & \\
\hline & 65 and over & $20,0 \%$ & $24,4 \%$ & $19,4 \%$ & $14,4 \%$ & $4,5 \%$ & & \\
\hline & Primary or lower & $10,1 \%$ & $11,1 \%$ & $9,0 \%$ & $13,0 \%$ & $8,7 \%$ & & \\
\hline Education & Secondary & $24,3 \%$ & $18,3 \%$ & $26,0 \%$ & $28,0 \%$ & $21,7 \%$ & 0,07 & 0,637 \\
\hline & Higher & $65,6 \%$ & $70,6 \%$ & $65,0 \%$ & $59,0 \%$ & $69,6 \%$ & & \\
\hline & $\begin{array}{l}\text { Significantly below the } \\
\text { average }\end{array}$ & $12,9 \%$ & $14,3 \%$ & $10,1 \%$ & $21,2 \%$ & $5,3 \%$ & & \\
\hline Income & Around the average & $57,4 \%$ & $45,2 \%$ & $61,6 \%$ & $61,2 \%$ & $63,2 \%$ & 0,14 & 0,008 \\
\hline & $\begin{array}{l}\text { Significantly above the } \\
\text { average }\end{array}$ & $29,7 \%$ & $40,5 \%$ & $28,3 \%$ & $17,6 \%$ & $31,6 \%$ & & \\
\hline & Student (school) & $\mathbf{9 , 3 \%}$ & $9,9 \%$ & $8,4 \%$ & $12,9 \%$ & $4,8 \%$ & & \\
\hline & Student (university) & $12,1 \%$ & $9,9 \%$ & $14,5 \%$ & $10,9 \%$ & $14,3 \%$ & & \\
\hline & Worker & $16,4 \%$ & $13,2 \%$ & $14,2 \%$ & $17,8 \%$ & $38,1 \%$ & & \\
\hline Occupancy & Employee & $29,1 \%$ & $25,7 \%$ & $30,0 \%$ & $32,7 \%$ & $28,6 \%$ & 0,11 & 0,166 \\
\hline & Manager/own business & $7,2 \%$ & $11,2 \%$ & $6,5 \%$ & $5,9 \%$ & $4,8 \%$ & & \\
\hline & Unemployed & $1,9 \%$ & $2,0 \%$ & $2,6 \%$ & $1,0 \%$ & $0,0 \%$ & & \\
\hline & Retired & $24,0 \%$ & $28,3 \%$ & $23,9 \%$ & $18,8 \%$ & $9,5 \%$ & & \\
\hline Total number of $\mathrm{r}$ & espondents** & 667 & 157 & 323 & 104 & 23 & & \\
\hline
\end{tabular}

The structure of respondents according to occupation (employment) is diverse. The majority of visitors are formed by employees $(29,1 \%)$ and workers $(16,4 \%)$ - a total of 
$45,5 \%$, followed by retirees $(24 \%)$ and students $(21,5)$-univerrsity students $(9,7 \%)$ and pupils $(11,8 \%)$. Behind are managers or business owners $(7,2 \%)$ and the unemployed $(1,9 \%)$. Bulgarian residents are featured by increased share of workers $(51 \%)$ and students (24\%) and a relatively low share of pensioners (18\%), while foreign visitors have a higher share of pensioners (between $31 \%$ and $36 \%$ in different country groups).

The surveyed visitors are dominated by middle- and high-income groups. $57 \%$ of the respondents rated their income as average for the counry, 30\% - as significantly higher than the average and $30 \%$ as significantly lower than the average. Substantial and statistically significant differences are found by country of origin as well as by most of the other characteristics of respondents (age, education, occupation). The middle-income group $(66,2 \%)$ is dominant among Bulgarian residents, the share of the group with significantly lower than the average income is higher $(17,7 \%)$ and of the the group with significantly higher than the average income - lower $(16,1 \%)$. Among non-residents, the groups with significantly higher than the average income $(48,4 \%)$ and the middle income $(45,3 \%)$ are almost equally represented, while the group with significantly lower than the average income is negligible $(6,3 \%)$. The differences between the groups of countries, are most evident in the share of the group with significantly higher than average income, which increases from $36 \%$ for neighboring countries to $47 \%$ for other European countries and $55 \%$ for others (distant) countries.

Somewhat surprising, education and occupation are not significantly correlated with the type of cultural tourist, but a more pronounced relationship between the type of cultural tourist and income is observed. Persons with an income well above the average are more often purposeful cultural tourists $(40,5 \%)$ and those with an average income - sightseeing tourists $(61,6 \%)$. Respondents with lower than average incomes show the highest share of incidental cultural tourists $(21,2 \%)$ and a significantly lower share of sightseeing tourists $(38,2 \%)$.

Table 3 presents the characteristics of the trip of the visitors of heritage attractions broken down by type of cultural tourist.

The purpose of the trips in which the respondents visited the heritage attractions is diverse. As expected visits classified as "cultural heritage tourism" are dominating $(55,3 \%)$, but near half of the visits are for other purposes, mainly recreation and entertainment $(21 \%)$ but also visits to cultural events $(4,7 \%)$, transit through the area $(3,8 \%)$, visiting friends and relatives $(3.3 \%)$, nature-based tourism $(2,6 \%)$, pilgrimage $(1,5 \%)$, attending conferences $(1,2 \%)$. Attendance to sporting events, practicing sporting activities and medical treatment are negligible (up to 0,5\%). In order to trace the relationship to other characteristics of tourists and trips, the summary grouping was used - "cultural heritage tourism", "recreation and entertainment" and "other". The differences in the structure of the visit by purpose are statistically significant by groups of countries, education, occupation, type of trip, organization and realization of the trip, as well as by the number of nights spent in the area, but not by sex, age, income, mode of transport, overnight stay in the area and average daily expenditure. However, the relationship is relatively weak (Cramer's V is between 0.13 and 0.19 ).

"Cultural heritage tourism" (55\% on average) is of greater importance for foreign visitors $(62,7 \%)$, especially for those from neighboring countries $(71,4 \%)$ and other (distant) countries $(70,3 \%)$, for respondents with primary and lower education $(72,3 \%)$, but also for those with higher education $(57,3 \%)$, students $(71,7 \%)$ and retired persons $(66,2 \%)$, being on round trips $(61,4 \%))$, when using a travel agency or other travel intermediary 
or organizer $(64,6 \%)$, when traveling with an organized group $(65.1 \%)$ and spending one night in the area $(66,4 \%)$.

"Recreation and entertainments" trips ( $21 \%$ on average) are characterized by an increased share of people living in Bulgaria $(25,6 \%)$, people with secondary education $(26,5 \%)$, workers $(27,9 \%)$ and employees $(23,5 \%)$, by trips with one main stay center $(29 \%)$, selforganized $(26,7 \%)$ and carried out individually $(26,5 \%)$, with more than 3 nights in the area $(31-33 \%)$.

Trips with "other" purposes ( $24 \%$ on average) indicate an increased share of people with secondary education (29\%), students $(39,7 \%$ - visits to cultural events, nature-oriented tourism, business, etc.), managers (32,6\% - business, cultural events, nature-oriented tourism), unemployed (33,3\% - visiting friends and relatives, pilgrimage), of trips with one main stay center $(30,1 \%)$ and more than 6 nights $(38,8 \%)$.

Table 3. Characteristics of the trip of the visitors of heritage attractions

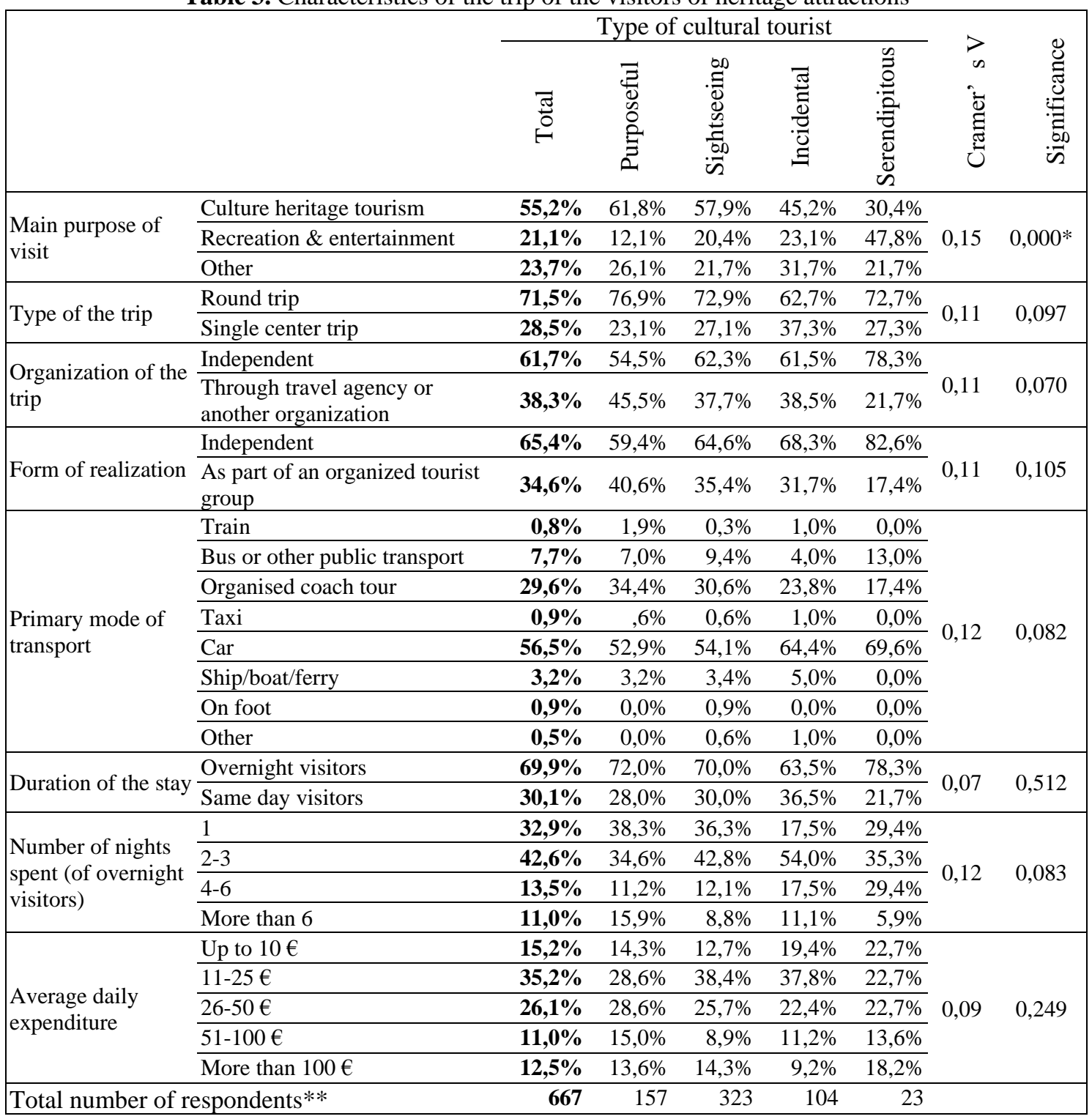

* Differences are significant at $\mathrm{p}<0,05$

** Incl. 60 non-classified cases not presented in the table 
The purpose of visiting the area is the sole trip characteristic with statistically significant differences by type of cultural tourist. "Cultural heritage tourism" visitors demonstrate slightly higher than the average share of purposeful cultural tourists $(26,4 \%)$ and lower of incidental ones $(12,8 \%)$. Visitors with "recreation and entertainment" purpose have a much lower than the average share of purposeful cultural tourists $(13,5 \%)$, but an increased share of serendipitous tourists as well $(7,8 \%)$. Visitors with "other" purposes have an increased share of incidental $(20,9 \%)$, but also of purposeful cultural tourists $(25,9 \%)$.

The majority of visitors to cultural heritage attractions were on a round trip (71,6\% versus $28,4 \%$ for trips with one main center of stay). Round trips are significantly higher than the average for foreign visitors $(86,3 \%)$, especially from other (distant) countries $(92,9 \%)$, for cultural and historical tourism $(79,1 \%)$, trips organized through a travel agency or other organizer $(90,8 \%)$ and realized in an organized group $(91,1 \%)$, for short term visitors (same day $-80,8 \%$ or with one night only - 79,3\%), and for visitors with an average daily expenditure of more than $100 €$. Visits with one main stay center are higher than the average for residents in Bulgaria $(37,8 \%)$, trips for leisure and recreation $(39,1 \%)$ and other purposes $(36,6 \%)$, independently organized $(40,4 \%)$ and realized trips $(38,9 \%)$, for overnight visits $(32,7 \%)$, especially with more than one night spent in the area $(58,3 \%)$, for visitors with low average daily costs - up to $10 €(40 \%)$ and $11-25 €(33,3 \%)$. $62 \%$ of the respondents organized the trip independently, and $38 \%$ used a travel agency or another organization (school, church). On the other hand, $65 \%$ of the respondents travel individually (including with family, with friends) and 35\% - as part of an organized group. The two characteristics are closely related (Cramer's $\mathrm{V}=0,88)$. Visitors from Bulgaria organize their trips mostly independently $(72 \%)$ and travel mostly individually $(74 \%)$. Foreign visitors are much more likely to organize the trip through a travel agency (54\%) and travel as part of an organized group (48\%). This is especially true for visitors from other (distant) countries (69\% and 65\% respectively). Organized trips are more typical for visitors with primary and lower education. $81 \%$ of them have organized their travel through a travel agency or other organizer, and travel as part of an organized group which is largely explained by respondents' occupation - organized trips are especially typical for pupils (85\% for both characteristics) and, at a lower level, for university students (50\%) and retirees $(54 \%)$.

Mostly cars were used to reach the visited attractions - 57\% (preferred by independent visitors $-84.3 \%$ and by trips with one main center of stay - 78\%) and tourist coaches $25 \%$ (typical for organized groups). The use of a ship (3\% of the total and $9 \%$ of organized groups) is related to visits of cruise tourists, mainly in Rousse.

$30 \%$ of the respondents are same-day visitors and $70 \%$ spend at least one night in the area. The overnight visitors have a relatively short stay - 33\% of them have spent 1 night, $43 \%$ - 2-3 nights. Bulgarian residents have a higher share of visits with 2-3 nights $(51 \%)$ and non-residents - of visits with one night (41\%), as well as with more than 6 nights $(15 \%)$. Round trips are characterized by much higher share of same-day visits (34\%) and visits with one night spent in the area (39\%), while trips with one main stay center demonstrate much higher share of overnight visitors $(80 \%)$ and twice higher than the average share of visits with more than 6 nights spent in the area (20\%).

The average daily expenditure relates to the trip as a whole and not to the visit in the area only allowing to distinguish between cheap (low budget) and expensive (luxury) trips. Nevertheless, indirectly, conclusions can be drawn about the spending in the area of attraction. The majority of visitors to cultural heritage attractions (61\%) have an average 
daily expenditure between 11-25 and 26-50 $€$. However, the other groups are not negligible - up to $10 €(15 \%), 51-100 €(11 \%)$ and over $100 €$ per day (12\%). Travel costs show statistically significant variations depending on almost all visitor and travel characteristics, the biggest being by country of origin of visitors - both in absolute terms and in terms of coefficient of association (Cramers's V) value. Furthermore, a more detailed analysis shows that differences in other characteristics are largely related to the structure by country of origin. A significant difference is observed between Bulgarian residents and non-residents. $91 \%$ of Bulgarian residents have average daily expenditure up to $50 €$, with higher share of the groups up to $10 €(24 \%)$ and $11-25 €(44 \%) .76 \%$ of foreign visitors have an average daily expenditure of over $25 €$ with a higher share in all three higher cost groups - 26-50€(31\%), 51-100€ (17\%) and over $100 €(28 \%)$.

Neighboring countries are featured by a higher than the average for foreign visitors share of cheaper trips - $11-25 €(32 \%)$ and $26-50 €(40 \%)$, while the distant countries have the highest expenses $-36 \%$ of the visitors fall in the group with more than $100 €$ per day. Other European countries are in the middle, showing an almost even distribution of visitors to all groups with average daily expenditure over $10 €$ per day.

\section{Sources of information about the visited attractions}

The information behavior of visitors to cultural tourist attractions was identified through two questions - whether they had preliminary information about the attraction visited and which specific sources of information about the attraction were used before the visit.

Nearly $90 \%$ of visitors were informed about the site prior to the visit. Statistically significant differences are found only by type of cultural tourists and average daily expenditure. Not surprisingly, more often sightseeing cultural tourists (12\%) and especially serendipitous cultural tourists $(26 \%)$ have no prior information compared to $6 \%$ for the purposeful cultural tourists. Only $2 \%$ of those employed in science and education have no prior information on the attraction visited. Visitors with the highest average daily expenditures - over $100 €$, more often have no prior information about the attraction visited - $23 \%$ (these are mainly cruise tourists from distant countries).

The specific sources of information about the attraction visited are presented in Figure 1. Respondents often used more than one source (average 1,5) to get preliminary information about the attractions visited. The main sources of information are the informal sources used in the place of residence, namely - comments and recommendations of relatives and friends $-45,8 \%$ of respondents and $31,4 \%$ of answers.

With similar values are the traditional formal sources, used exclusively in the place of residence (45,3\% of respondents and $31,1 \%$ of answers), which are usually divided into two groups - sources of general nature, such as mass media, books, etc. (27,5\% of respondents and $18,9 \%$ of answers) and tourist oriented, commercial as advertising brochures or information from travel agencies (17,8\% of respondents and 12,2\% of answers). In the group of traditional sources of general nature worth mentioning is the low presence of newspapers and television (about $2 \%$ of respondents) and the relatively high share of scientific literature (8.3\% of respondents), travel guides $(7,8 \%)$ and school $(5,3 \%)$. In the group of commercial sources, direct information from travel agencies $(15,4 \%$ of respondents) is much higher than advertising brochures $(2,4 \%)$.

$37,7 \%$ of respondents with $25,8 \%$ of answers used information from the Internet. Internet sources can be divided into two groups - general or non-specialized (16,6\% of respondents and $11,4 \%$ of answers) and specialized or tourist $(21,1 \%$ of respondents and $14,4 \%$ of answers). In the group of non-specialized Internet sources the largest share is 
accounted for Wikipedia (7,1\% of respondents) and social networks $(6,1 \%$ of respondents), and among the specialized prevail the international tourist websites $(8,3 \%$ of respondents) and national tourist websites $(7,6 \%)$. The share of own websites for tourist attractions $(3,1 \%)$, local tourist websites $(1,4 \%)$ and specific mobile applications $(0,7 \%)$ is very low - in the pre-determined answers "I love Bulgaria" is explicitly stated.

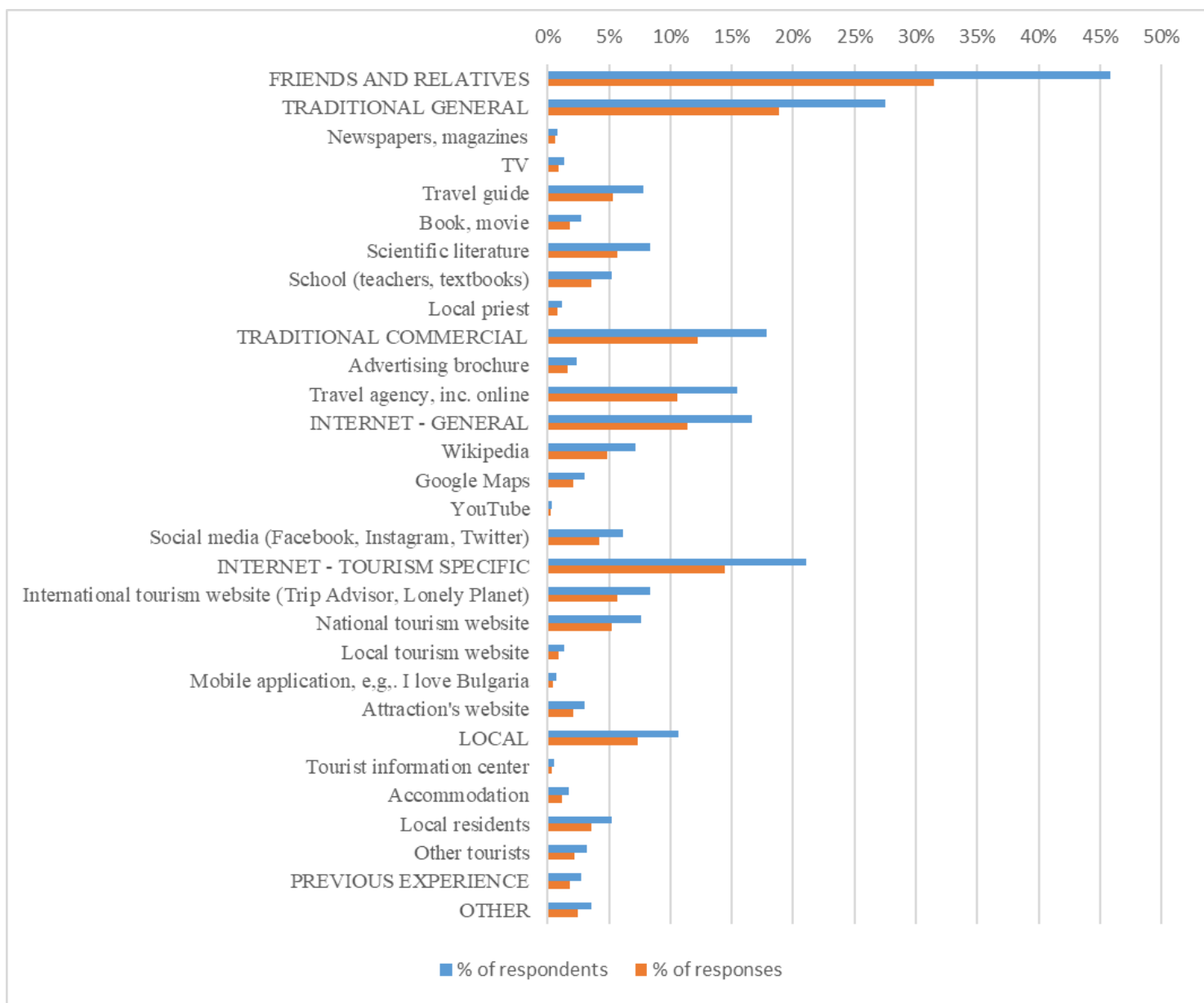

Figure 1. Sources of prior information about the visited cultural heritage attractions

A considerable number of visitors to cultural heritage attractions seek information about them on the spot, in the destination (10,7\% of respondents and 7,3\% of responses) mainly from locals $(5,3 \%)$ or other tourists $(3,2 \%)$ and much less from the accommodation establishments $(1,7 \%)$ and especially from the tourist information center $(0,5 \%)$.

Provided that much of the differences depending on visitor and travel characteristics are not statistically significant, some of them are considered to be larger and more interesting from a practical point of view:

- Purposeful and serendipitous cultural tourists are less likely to use family and friends as their information source (37\% and 35\%) and more often rely on traditional general sources (40\% and $41 \%$ ), especially guidebooks (12\% and 18\%) and scientific literature (12\% both). In addition, purposeful cultural tourists are less frequently informed on-site (7\%), and serendipitous tourists get more often informed by common Internet sources (24\%) and less frequently by traditional commercial sources $(6 \%)$. 
- Visitors from Bulgaria are more often informed by friends and relatives (56\% vs. 29\% for residents abroad), by scientific literature (12\% vs. 3\%), and by school (9\% vs. $0 \%$ ) and on-site, in the destination ( $13 \%$ vs. $7 \%$ ), and much less frequently by traditional commercial sources such as travel agencies (9\% vs. 33\%) and the Internet (26\% vs. $56 \%$ ). Two interesting dependencies related to the remoteness (spatial and/or cultural) of the countries are identified. The weight of friends and relatives as a source of information decreases from $56 \%$ for Bulgaria and $35 \%$ for neighboring countries, to $30 \%$ for other European countries and $27 \%$ for other (distant) countries. Receiving information on-site in the destination decreases from 13\% for Bulgaria and 12\% for neighboring countries to $9 \%$ for other European countries and $4 \%$ for other (distant) countries.

- As expected, the oldest visitors use twice less Internet sources (20\% versus an average of 38\%). But there are some "surprises" in terms of age structure. The 15-24 age group uses the Internet as a source of information on cultural heritage attractions less than the average ( $28 \%$ vs. $38 \%$ on average), and the school $(21 \%)$ is a particularly important source for them. The Internet is mostly used by the groups aged 25-34 (53\%), 35-44 (45\%) and 45-54 (51\%).

\section{CONCLUSION}

The presented study applied the slightly modified model of McKercher [21] in order to classify the tourists at specific cultural heritage attractions in Bulgaria and to explore their characteristics. Based on the results the following conclusions could be drawn:

- Regarding the structure/profile of visitors and trips

The analysis of respondents' structure by nationality and permanent residence shows that the studied cultural heritage attractions have an international and national market, respectively they could be categorized as being of national or global significance (in terms of market demand). However, this does not predetermine similar categorization of each individual attraction included in the study.

Nearly $63 \%$ of the respondents are Bulgarians and foreigners are just over $37 \%$, but it is worth pointing out that for $61 \%$ of the respondents the usual place of residence is in Bulgaria, and for 39\% - in another country. Between $9 \%$ and $25 \%$ (for the different study areas) of Bulgarian visitors account for local demand as they belong to the respective administrative region. Foreigners originate from 35 countries but most numerous are the visitors from other European countries (54\%), mainly from Germany (9\%), UK (7\%), Switzerland, Spain and Italy (6\% each). The distant markets $(38 \%)$ are represented mainly by USA (23\%), Australia (5\%), Japan (4\%), Canada and China ( $2 \%$ each). The appointed structure of respondents is quite different from the typical for Bulgaria (according to border statistics data) and is characterized by an increased share of distant markets and a decreased share of some leading markets from Europe (especially Germany and Russia) and the neighboring countries. Due to the specifics of the survey (sample, relatively limited area, limited period) the results cannot be considered as absolute, but they at least indicate the structural features of the tourist flow visiting the Bulgarian cultural heritage attractions. From tourism policy point of view this structure means that cultural heritage tourism may serve as a tool not only for product diversification of Bulgarian tourism and reducing the space and time concentration, but also for market diversification. 
The survey results strongly acknowledge the widespread view in the literature that visitors to cultural heritage attractions have higher education and higher income. 2/3 of the respondents are university graduates - . The share of university graduates among Bulgarian visitors is 2,3 times higher than their share in the population of the country and among European visitors - 3 times higher than that of the EU population. The surveyed visitors are dominated by middle- and high-income groups. 57\% of the respondents rated their income as average for the counry, 30\% - as significantly higher than the average. The middle-income group (66\%) is dominant among Bulgarian residents, while among non-residents, the groups with significantly higher than the average income (48\%) and the middle income (45\%) are almost equally represented. On the other hand, the results regarding the age structure of the visitors differ from the dominant ones in the literature. The highest is the share of the youngest (15-24 years $-22 \%$ ) and of the oldest (65 years and over - 20\%). Among the Bulgarians, the share of the youngest is higher (15-24 years $-26 \%)$ and the share of the oldest is reduced (65 years and over $-14 \%)$. On the contrary, the share of the oldest is higher among foreigners $(28 \%)$.

Visitors to cultural heritage attractions in general demonstrate an increased share of the use of intermediaries in the organization of travel (38\%) and of group travel (35\%). This is especially true for foreign visitors - 54\% of them are likely to organize the trip through a travel agency and $48 \%$ travel as part of an organized group. Bulgarians are far more inclined to organize their trips independently (72\%) and to travel mostly individually (74\%). For organized trips, especially in a group, the choice of tourist attractions is largely determined by the organizer. This predetermines directing marketing efforts not only to individuals but also to intermediaries.

The widespread use of individual motor vehicles (57\%) and tourist buses (25\%) implies the availability of organized parking in the area of tourist attractions.

- Regarding information sources

The leading role of the informal sources in the place of residence, namely - comments and recommendations of relatives and friends (46\% of respondents and $31 \%$ of answers) - emphasizes the need of focusing on product design and delivery and achiving high level of satisfaction and memorable experiences and not only on communication and advertising. The data also show a clear need to expand and improve the online presence, especially to inform and attract foreign visitors (38\% of all respondents and $56 \%$ of foreiners have used Internet to get prior information about the attraction). In this respect, the low proportion of local websites and of the own websites of attractions is problematic. The possible reasons and respectively the main areas of improvement are the scope and quality of information provided and the easy detection (Search Engine Optimization). Finally, 10\% of respondents were informed on the attraction visited on-site in the destination, but mainly from infomal sources. This indicates the need to improve the local dissemination of information on cultural heritage attractions.

- Regarding the typology of cultural tourists

The differences in the profile of the various types of cultural tourist are not large, nor are the differences in the structure by types of cultural tourist of the groups derived from the characteristics of the visitors and/or their trips. The relationship of the types to some of the demographic characteristics is closer than to the characteristics of the trips, i.e. the type of cultural tourist does not significantly affect these aspects of tourist behavior. But, as further analysis shows, the type of cultural tourist is in many cases 
one of the most important explanatory variables for differences in other aspects of tourist behavior: the importance of different elements and characteristics of cultural heritage when choosing a destination, the importance of the attributes of tourist attractions, sources used for preliminary information, satisfaction and quality of experience evaluation, and especially attributive satisfaction.

Similar to the results of our own research are the findings of McKercher [21], who, citing other authors, considered that the discussed characteristics of individuals and trips were not appropriate for segmenting the cultural tourism market. According to his research, the most significant are the differences by country, especially in terms of their physical and cultural distance - visitors from more distant countries are more likely to have greater share of purposeful cultural tourists. At the same time, McKercher [21] found differences in other aspects of tourist behavior, especially in terms of preferred attractions and places and the intensity of the tourist experience.

Finally, as stated above, the presented reseach suffers a number of limitations in terms of sample, relatively limited area and limited survey period. To make the results more representative and reliable, future field research is planned to cover other regions and seasons.

\section{Acknowledgement}

The research was supported by the Bulgarian Ministry of Education and Science under Cultural Heritage, National Memory and Society Development National Research Program, approved by DCM No 577/17 August 2018.

\section{REFERENCES}

[1] Explica-Global Metrics. Cultural tourism - product analysis. 2019 http://www.tourism.government.bg/bg/kategorii/za-obshtestveno-obsuzhdane/produktovianalizi-i-planove-za-razvitie-na-kulturniya-i-na

[2] Explica-Global Metrics. Cultural tourism - plan for development in 2020-2025. 2019 (draft) http://www.tourism.government.bg/bg/kategorii/za-obshtestveno-obsuzhdane/produktovianalizi-i-planove-za-razvitie-na-kulturniya-i-na

[3] Veverka, J. A. (2001) Marketing Basics for Interpretive \& Heritage Sites and Attractions It's all about the visitors. Handout for the training courses: Destination Interpretation and Marketing: Secrets of Success taught at New York University and Marketing Heritage Tourism \& Interpretive Sites, Agencies and Attractions, taught at Snowdonia National Park Training Center, $\quad$ Wales. $2001 \quad$ https://portal.unifreiburg.de/interpreteurope/service/publications/recommendedpublications/veverka_marketing_basics.pdf

[4] Schouten, F. Managing Visitors: Helping the Frail to Prevail. NHTV Internationale Hogeschool Breda. 2005 http://wwwdata.unibg.it/dati/corsi/44108/50650-NHTV\%20Frans1.pdf

[5] European Commission, Directorate - General Enterprise - the Tourism Unit. Using natural and cultural heritage to develop sustainable tourism. 2002.

[6] Speno, L., L. Burns, M.A. Eaddy, C. Moore, H. Talley-McRae. Heritage Tourism Handbook: A How-to-Guide for Georgia. Georgia Department of Natural Resources, Georgia Department of Economic Development, 2010. https://www.georgia.org/sites/default/files/wpuploads/2013/09/GA-Heritage-Tourism-Handbook.pdf

[7] Failte Ireland. A Tourism Toolkit for Ireland's Built Heritage: How to Develop \& Promote Heritage Attractions for Visitors. (no year) http://www.failteireland.ie/getmedia/3799df7f-a9364527-8d30-b64f223248ab/FI-Heritage-Tourism-Toolkit-with-Activated-Exercises-(2).aspx 
[8] Texas Historical Commission. Heritage Tourism Guidebook. (no year) https://www.thc.texas.gov/public/upload/publications/heritage-tourism-guide.pdf

[9] Whyte, B., T. Hood, B. White (Eds.). Cultural and Heritage Tourism: A Handbook for Community Champions. Federal Provincial Territorial Ministers of Culture and Heritage, 2012. https://tourismns.ca/sites/default/files/page_documents/cultural_heritage_tourism_handbook.pdf

[10] Yan, G., Sl. So, A.M. Morrison, Y.H. Sun. 2007. Activity Segmentation of the International Heritage Tourism Market to Taiwan. - Asia Pacific Journal of Tourism Research, 12 (4), pp. 333347, 2007.

[11] Cetin, G., \& Bilgihan, A. (2014). Components of cultural tourists' experiences in destinations. Current Issues in Tourism, 19 (2), pp. 137-154, 2014. DOI: $10.1080 / 13683500.2014 .994595$.

[12] Richards, G. Cultural tourism Richards, G. Tourism trends: The convergence of culture and tourism trends in Europe: a context for the development of Cultural Routes. In: KhovanovaRubicondo, K. (ed.) Impact of European

Cultural Routes on SMEs' innovation and competitiveness.

Strasbourg: Council of Europe Publishing, 2011, pp. 21-39. http://www.coe.int/t/dg4/cultureheritage/culture/routes/StudyCR_en.pdf

[13] Richards, G. Tourism trends: The convergence of culture and tourism. Academy for Leisure, NHTV University of Applied Sciences, 2014.

[14] Richards, G. The role of gastronomy in tourism development. Presentation to the Fourth International Congress on Noble Houses: A Heritage for the Future, Arcos de Valdevez, 27- 29 November 2014.

2014 https://www.academia.edu/6962785/The_role_of_gastronomy_in_tourism_development[15]

Richards, G. Creative Tourism Trend Report. Volume 1, 2015. http://www.atlaswebshop.org/creative-tourism-trend-report-volume-1

[16] Richards, G. Cultural Tourism: A review of recent research and trends. - Journal of Hospitality and Tourism Management, Volume 36, September 2018, pp. 12-21 https://www.sciencedirect.com/science/article/pii/S1447677018300755

[17] Xie, P., G. Wall. Visitors' perceptions of authenticity at cultural attractions in Hainan, China. International Journal of Tourism Research 4, p. 353-366, 2002. DOI: 10.1002/jtr.385

[18] Cenderello, A. Marketing of heritage sites. H.I.S.A. Study, 2015 http://www.interpreteurope.net/fileadmin/Documents/projects/HISA/HISA_Marketing_Heritage_sites.pdf

[19] Nyaupane, G.P., K.L. Andereck. A typology of cultural heritage attraction visitors. - Travel and Tourism Research Association: Advancing Tourism Research Globall, 63, 2016. https://scholarworks.umass.edu/ttra/2007/Presented_Papers/63

[20] Nyaupane, G.P., D.D. White, M. Budruk. Motive-Based Tourist Market Segmentation: An Application to Native American Cultural Heritage Sites in Arizona, USA. - Journal of Heritage Tourism, 1 (2), pp. 81-99, 2006.

[21] McKercher, B. Towards a classification of cultural tourists. International Journal of tourism research 4. pp. 29-38, 2002. DOI: 10.1002/jtr.346

[22] McKercher, B., H. du Cros. Testing a Cultural Tourism Typology. International Journal of Tourism Research, 5, pp. 45-58, 2003. DOI: 10.1002/jtr.417

[23] Marinov, V., M. Assenova, V. Nikolova, E. Petkova, R. Mitova, A. Kazakov, Ch. Istatkova. Typology of cultural heritage attractions in Bulgaria: Theorethical and management implications. - In: Tourism in the VUCA world: Towards the era of (ir)responsibility. International tourism conference Dubrovnik, 6-9 November 2019. Book of abstracts. Institute for Tourism, Zagreb. Zagreb, 2019, p. 75 